\title{
Adjunctive treatment with oral AKLI, a botanical nutraceutical, in chronic obstructive pulmonary disease
}

This article was published in the following Dove Press journal:

International Journal of COPD

9 July 2014

Number of times this article has been viewed

\author{
Claire Brockwell' \\ Sundari Ampikaipakan ${ }^{1,2}$ \\ Darren W Sexton' \\ David Price ${ }^{3,4}$ \\ Daryl Freeman ${ }^{5}$ \\ Mike Thomas ${ }^{6}$ \\ Muzammil Ali ${ }^{4}$ \\ Andrew MWilson ${ }^{1,2}$
}

'Norwich Medical School, University of East Anglia, Norwich, UK; ${ }^{2}$ Norfolk and Norwich University Hospital Foundation Trust, Norwich, UK;

${ }^{3}$ Academic Primary Care, University of Aberdeen, Aberdeen, UK; ${ }^{4}$ Research in Real Life, Cambridge, UK; ${ }^{5}$ Mundesley Medical Centre, Mundesley, Norwich, UK; ${ }^{6}$ Primary Care Research,

Aldermoor Health Centre, University of Southampton, Southampton, UK

Correspondence: Andrew M Wilson Norwich Medical School, Medical School Building, University of East Anglia, Norwich, NR4 7TJ, UK

Tel +44 I603 59I 257

Fax +44 I603 59I 750

Email a.m.wilson@uea.ac.uk
Purpose: The objective of this pilot trial was to evaluate the safety and efficacy of AKL1, a patented botanical formulation containing extracts of Picrorhiza kurroa, Ginkgo biloba, and Zingiber officinale, as add-on therapy for patients with chronic obstructive pulmonary disease (COPD) and chronic cough.

Patients and methods: This randomized, double-blind, placebo-controlled trial enrolled male and female patients $>18$ years old with COPD and Leicester Cough Questionnaire (LCQ) score of $<18$. The 10 -week study period comprised a 2 -week single-blind placebo run-in period followed by add-on treatment with AKL1 or placebo twice daily for 8 weeks. The primary study endpoint was the change from week 0 to week 8 in cough-related health status, as assessed by the LCQ.

Results: Of 33 patients enrolled, 20 were randomized to AKL1 and 13 to placebo. Patients included 19 (58\%) men and 14 (42\%) women of mean (standard deviation [SD]) age of 67 (9.4) years; 15 (45\%) patients were smokers and 16 (49\%) were ex-smokers. The mean (SD) change from baseline in LCQ score at 8 weeks was 2.3 (4.9) in the AKL1 group and 0.6 (3.7) in the placebo group, with mean difference in change of 1.8 (95\% confidence interval: -1.5 to 5.1 ; $P=0.28)$. The St George's Respiratory Questionnaire score improved substantially in the AKL1 treatment group by a mean $(\mathrm{SD})$ of -7.7 (11.7) versus worsening in the placebo group $(+1.5$ [9.3]), with mean difference in change of -9.2 ( $95 \%$ confidence interval: -19.0 to $0.6 ; P=0.064)$. There were no significant differences between treatment groups in change from baseline to week 8 in other patient-reported measures, lung function, or the 6-minute walk distance.

Conclusion: Further study is needed with a larger patient population and over a longer duration to better assess the effects of add-on therapy with AKL1 in COPD.

Keywords: Leicester Cough Questionnaire, anti-inflammatory, Picrorhiza kurroa, Ginkgo biloba, Zingiber officinale

\section{Introduction}

The goal of pharmacologic therapy for chronic obstructive pulmonary disease (COPD) is to control symptoms, reduce exacerbation frequency, and improve quality of life; however, the results of standard pharmacologic therapy are often unsatisfactory, manifesting as restricted activity and impaired quality of life, as well as exacerbations and hospitalizations. ${ }^{1}$ Patients often show poor adherence to and persistence with COPD regimens; ${ }^{2-4}$ their concerns about chronic therapy for COPD frequently center around lack of confidence in the efficacy and safety of medications. ${ }^{4,5}$

Inhaled bronchodilators are currently the mainstay of COPD therapy. The need for concomitant anti-inflammatory therapy is well recognized; however, the majority 
of patients with COPD show corticosteroid resistance, and the optimal means of treating the underlying airway inflammation in COPD remains under active investigation. ${ }^{6-9}$ Patients with COPD often use complementary and alternative medicines. ${ }^{4,10}$ Herbal medicines have been used for centuries in the People's Republic of China and other parts of Asia for treating respiratory diseases, and many natural agents have anti-inflammatory effects. ${ }^{7,11,12}$

A new patented formulation, AKL1 (AKL International, Ltd, Guernsey, UK), comprising standardized extracts of Picrorhiza kurroa, Ginkgo biloba, and Zingiber officinale, has been developed as adjunctive therapy for patients with obstructive lung disease (COPD and asthma). The active compounds picroliv, androsin, and apocynin contained in P. kurroa, an herb used in Ayurvedic medicine to treat liver and lung diseases, have demonstrated anti-inflammatory activities. In vitro, picroliv inhibits the nuclear factorkappaB activation pathway, ${ }^{13}$ while in guinea pigs, androsin prevents bronchial obstruction induced by allergen and platelet-activating factor. ${ }^{14}$ Apocynin abrogates the agonistinduced contraction of airway smooth muscle from patients with asthma by blocking the activation of nicotinamide adenine dinucleotide phosphate oxidase; in patients with mild asthma, nebulized apocynin reduces the concentration of reactive oxygen and reactive nitrogen species in exhaled breath condensate. ${ }^{15,16}$ Extracts of $G$. biloba ameliorate eosinophilic inflammation in lung epithelia and suppress nuclear factor-kappaB activation, ${ }^{17,18}$ as well as reduce levels of interleukin-5 and inflammatory cells containing protein kinase $\mathrm{C}$ (eosinophils and lymphocytes) in induced sputum when given in addition to inhaled corticosteroids to patients with asthma. ${ }^{19}$

The AKL1 formulation, not yet available commercially, is manufactured using strict standardization of its individual botanical components against specific proprietary phytochemical markers to ensure batch-to-batch consistency, as previously described. ${ }^{20}$ The results of a small pilot study ${ }^{20}$ suggest that AKL1 may be efficacious as adjunctive therapy for patients with asthma to improve symptoms and quality of life. Patient-centered outcomes, including the Leicester Cough Questionnaire (LCQ) scores, showed trends to improvement with AKL1 relative to placebo. ${ }^{20}$ Our objective in this trial was to evaluate the safety and efficacy of AKL1 as add-on therapy for patients with COPD who had chronic cough despite their current management. Our hypothesis was that AKL1 would improve cough-related quality of life as assessed using the LCQ.

\section{Methods}

\section{Trial design}

This randomized, double-blind, placebo-controlled, parallelgroup trial was conducted from June 2009 through February 2011 at a single site at the University of East Anglia, Norwich, UK. The 10-week study period comprised a 2-week singleblind placebo run-in period (to identify nonadherent patients and minimize the placebo effect during the study) followed by an 8-week treatment period. Four study visits were scheduled: 1) at the start of the run-in period (week -2);2) at baseline (week 0); 3) after 4 weeks' treatment (week 4); and 4) at study end (week 8). The study duration of 8 weeks was chosen because we expected to find clinically relevant improvements during this time period, based on results of an earlier pilot study (Freeman et al, unpublished data, 2007).

During the 2-week screening period from visit 1 to visit 2 , all patients received single-blind placebo in addition to their usual treatment. Patients who remained eligible for the study at baseline (week 0 ) were randomly assigned in a 1:1 ratio, using a block randomization procedure with block size of four (not known to investigators), to receive oral AKL1 or placebo in addition to their current medication. Randomized treatment consisted of AKL1 or identical placebo (containing calcium phosphate and magnesium stearate) taken as two capsules twice daily at the same time each morning (7 am to $10 \mathrm{am}$ ) and each evening (7 pm to $10 \mathrm{pm})$. The AKL1 administered in this study was produced according to UK Good Manufacturing Practices. ${ }^{21}$

\section{Patients}

Patients eligible for the study were male and female adults ( $>18$ years old) who had a diagnosis of obstructive lung disease and nonreversible airflow limitation, as defined by a postbronchodilator ratio of forced expiratory volume in 1 second $\left(\mathrm{FEV}_{1}\right)$ to forced vital capacity of $<0.7^{22}$ at visit 2 . In addition, at visit 1 or 2 , all eligible patients had a postbronchodilator $\mathrm{FEV}_{1}$ of $<80 \%$ and evidence of persistent symptoms as 1) an LCQ score of $<18$; and 2) a modified Medical Research Council (MRC) dyspnea score of $\geq 3$ or a modified MRC dyspnea score of $\geq 2$ plus Clinical COPD Questionnaire (CCQ) score $\geq 1.5$.

Enrolled patients were required to be in satisfactory health other than obstructive lung disease, as determined by investigators on the basis of medical history and physical examination. In addition, during the screening period, eligible patients had to demonstrate satisfactory ability to use a salbutamol metered-dose inhaler. Female patients had 
to be $>1$ year postmenopausal, surgically sterilized, or, if of childbearing potential, using adequate contraception, not breastfeeding, and testing negative for pregnancy on a urine test.

Smokers were not excluded from the study. Key exclusion criteria were maintenance oral corticosteroids, seasonal disease, or an exacerbation or recent change in maintenance therapy within 6 weeks before visit 1 . Patients unable to discontinue short-acting $\beta$-agonists for at least 4 hours, long-acting $\beta$-agonists for 12 hours, or tiotropium for 48 hours before visit 2 (baseline) were also excluded. Any other severe acute or chronic medical or psychiatric condition that, in the judgment of the investigator, would make the patient inappropriate for entry into the study was cause for exclusion.

Antibiotics were not permitted within 6 weeks before the study. Medications not allowed for 3 months before and during the study included oral anticoagulants, antiepileptic medication, long-term systemic corticosteroids, long-term oxygen therapy (to exclude the most severe patients), and other investigational drugs. Other treatments prescribed for concomitant diseases not interfering with the study evaluations were allowed during the trial period, providing their use did not change during the study. Oral corticosteroids for 2 weeks and antibiotics could be prescribed during the study as medically necessary.

The study was conducted in accordance with Good Clinical Practice including Research Ethics Committee (08/H0305/54) and Medicines and Healthcare products Regulatory Agency (2222-222222-22) approval, and all participating patients gave written informed consent. The study was registered on the ClinicalTrials.gov website. ${ }^{23}$

\section{Procedures and study outcome measures}

The primary study endpoint was the change from week 0 to week 8 in cough-related health status, as assessed by the LCQ. ${ }^{24}$ The LCQ is a self-administered instrument comprising 19 items, each scored on a 7-point Likert-type scale from 1 (worst status) to 7 (best status) and averaged within three domains (physical, psychological, and social). The three domain scores are then totaled for a final score ranging from 3 to 21 , with higher score indicating a better health-related quality of life. ${ }^{24}$ The minimal clinically important difference (MCID) for the LCQ is $1.3 .^{25}$

Secondary endpoints included the COPD-specific health status using the St George's Respiratory Questionnaire (SGRQ), on which scores range from 0 to 100 , with lower scores indicating improvement and an MCID of 4 units; $;^{26,27}$ the CCQ score, which ranges from 0 (best) to 6 (extremely symptomatic/total limitation) with MCID of $0.4 ;^{28-31}$ and the modified MRC dyspnea score, scored from 1 (breathless only with strenuous exercise) to 5 (too breathless to leave the house or breathless when dressing or undressing). ${ }^{32-34}$ In addition, we assessed exercise impairment as measured by the 6-minute walk distance test. ${ }^{35,36}$

At visit 1, after informed consent was obtained, a complete medical history was taken, a physical examination was performed, clinical laboratory tests were drawn, and patients were assessed for trial eligibility. Screening respiratory testing included spirometry, the 6-minute walk test, and administration of the LCQ, SGRQ, and modified MRC questionnaires. Spirometry was performed according to American Thoracic Society and European Respiratory Society guidelines. ${ }^{37,38}$

Testing at week 0 and week 8 included spirometry, the 6-minute walk test, and four questionnaires (LCQ, SGRQ, CCQ, and modified MRC). Testing at visit 3, after 4 weeks on AKL1 or placebo, included spirometry and the LCQ and SGRQ.

Salbutamol metered-dose inhalers were provided as rescue medication at visit 1 and throughout the study period as needed. Adverse events were monitored at each study visit, and liver and kidney function were assessed at the first and last visit.

\section{Statistical analysis}

The primary efficacy endpoint was the change in LCQ score between week 0 and week 8 . Sample size calculations were based on pilot study results ${ }^{20}$ and assuming a clinically important change in the LCQ of 0.5, with standard deviation (SD) of 1.04 for the change. We calculated that to achieve $80 \%$ power at a significance level of 5\%,69 evaluable patients in each arm were required, for a total of 82 patients per study arm, allowing for $15 \%$ drop-outs. Using the newer clinically important difference of 1.3 units, ${ }^{25}$ a sample size of 22 patients would be required.

Summary statistics were used to examine differences in baseline and outcome variable distributions between treatment groups. The primary analysis was conducted using an intention-to-treat approach, including all randomized patients, comparing baseline (visit 2) and outcome (visit 4) results using analysis of variance; we used the $\chi^{2}$ test for categorical variables. A separate analysis using Student's $t$-test was carried out to test the differences, with $95 \%$ confidence 
intervals (CIs), between the two arms in mean change from baseline to outcome in key variables.

In addition, because of missing data, we performed an exploratory analysis using the last-observation-carriedforward (LOCF) approach, allowing visit 1 values for baseline and visit 3 for outcome when visit 2 or 4 values, respectively, were missing.

Statistically significant results were defined as $P<0.05$. Statistical analyses were conducted using SPSS software (v 19; IBM Corporation, Armonk, NY, USA).

\section{Results}

\section{Patients}

A total of 78 patients were screened for the study at eleven sites/practices; of these, 33 (42\%) patients were enrolled in the study at the University of East Anglia site, and 32 of the 33 patients attended all four visits (one patient completed only the first three visits). Patients ranged in age from 41 to 80 years (mean [SD] 67 [9.4] years) and included 19 (58\%) men and 14 (42\%) women. Body mass index ranged from 18 to $39 \mathrm{~kg} / \mathrm{m}^{2}$ (mean [SD] 28.1 [5.4] kg/m²). Most patients were current smokers (15 [45\%]) or ex-smokers (16 [49\%]); two $(6 \%)$ patients had never smoked. The majority of patients were receiving inhaled corticosteroids and long-acting bronchodilators with or without tiotropium therapy.

Patient demographic and baseline clinical characteristics are summarized in Table 1. The two treatment groups were similar with regard to mean lung function measures (see Table 1), with $\mathrm{FEV}_{1}$ \%predicted ranging from $20 \%$ to $80 \%$ in the AKL1 treatment group and from $20 \%$ to $79 \%$ in the placebo group. Patient-reported measures tended to be worse in the AKL1 group, with LCQ score range from 6.5 to 16.7 at baseline, compared with 10.2 to 19.8 in the placebo group. Similarly, the SGRQ, for which a higher score is worse, ranged from 36 to 86 in the AKL1 treatment group and from 20 to 73 in the placebo group. The means at baseline are reported in Table 1 .

\section{Health-related quality of life: patient-reported measures}

There was no significant difference between treatment groups in the change from baseline in the LCQ score at 8 weeks, the primary endpoint (Table 2). Changes in the CCQ and the MRC dyspnea scores were also similar for patients who received AKL1 or placebo. The SGRQ improved substantially more in the AKL1 treatment group than in the placebo group, falling by a mean of 7.7 points as compared with a
Table I Baseline demographic and clinical characteristics of enrolled patients

\begin{tabular}{|c|c|c|c|c|}
\hline & \multicolumn{2}{|c|}{ AKLI $(\mathrm{N}=20)$} & \multicolumn{2}{|c|}{ Placebo $(\mathrm{N}=13)$} \\
\hline & $\mathbf{n}$ & $\begin{array}{l}\text { Mean (SD) } \\
\text { or } n(\%)\end{array}$ & $\mathbf{n}$ & $\begin{array}{l}\text { Mean (SD) } \\
\text { or } n(\%)\end{array}$ \\
\hline Age (years) & 20 & $66.9(11.1)$ & 13 & $67.3(6.5)$ \\
\hline Male sex $\mathrm{n}(\%)$ & 20 & $12(60)$ & 13 & $7(54)$ \\
\hline Body mass index $\left(\mathrm{kg} / \mathrm{m}^{2}\right)$ & 20 & $27.0(4.3)$ & 13 & $30.0(6.6)$ \\
\hline Smoking status n (\%) & 20 & & 13 & \\
\hline Current smoker & & $10(50)$ & & $5(39)$ \\
\hline Ex-smoker & & $9(45)$ & & $7(54)$ \\
\hline Nonsmoker & & I (5) & & I (8) \\
\hline \multicolumn{5}{|c|}{ Baseline spirometry, post-bronchodilator ${ }^{a}$} \\
\hline $\mathrm{FEV}_{1}(\mathrm{~L})$ & 18 & $\mathrm{I} .5(0.7)$ & 12 & $1.6(0.6)$ \\
\hline $\mathrm{FEV}_{1}$ (\%predicted) & 19 & $57.9(17.2)$ & 12 & $57.3(16.3)$ \\
\hline 6-minute walk distance $(\mathrm{m})$ & 20 & $294(181)$ & 13 & $347(145)$ \\
\hline Leicester Cough & 19 & $12.1(3.0)$ & 13 & $14.6(2.5)$ \\
\hline \multicolumn{5}{|l|}{ Questionnaire score } \\
\hline SGRQ total score, units & 17 & $62.5(14.7)$ & 11 & $54.3(16.2)$ \\
\hline SGRQ - symptoms domain & & $75.7(16.1)$ & & $65.0(17.7)$ \\
\hline SGRQ - activity domain & & $79.9(17.1)$ & & $68.9(21.6)$ \\
\hline SGRQ - impact domain & & $48.8(16.5)$ & & $42.4(16.1)$ \\
\hline Clinical COPD & 20 & $3.3(1.0)$ & 13 & $2.9(1.1)$ \\
\hline \multicolumn{5}{|l|}{ Questionnaire score } \\
\hline Modified MRC dyspnea score & 20 & $3.0(0.6)$ & 12 & $3.2(0.4)$ \\
\hline Medications at baseline $\mathrm{n}(\%)$ & 20 & & 13 & \\
\hline SABA only & & I (5) & & I (8) \\
\hline ICS only & & I (5) & & $2(15)$ \\
\hline LABA only & & I (5) & & 0 \\
\hline LAMA only & & $3(15)$ & & $2(15)$ \\
\hline $\mathrm{ICS}+\mathrm{LABA}$ & & $6(30)$ & & $3(23)$ \\
\hline$I C S+L A B A+L A M A$ & & $6(30)$ & & $2(15)$ \\
\hline Missing & & $2(10)$ & & $3(23)$ \\
\hline
\end{tabular}

Notes: Values expressed as means (SD) unless otherwise noted. ${ }^{a} A l l$ patients had an $\mathrm{FEV}, / \mathrm{FVC}$ ratio of $<0.7$ at visit 2 (baseline).

Abbreviations: $\mathrm{FEV}_{1}$, forced expiratory volume in I second; FVC, forced vital capacity; ICS, inhaled corticosteroid; LABA, long-acting $\beta$-agonist; LAMA, longacting muscarinic antagonist; MRC, Medical Research Council; SABA, short-acting $\beta$-agonist; SD, standard deviation; SGRQ, St George's Respiratory Questionnaire.

mean increase of 1.5 points for placebo $(P=0.064)$; however, the SGRQ analyses included just 13 of 20 patients and nine of 13 patients in the AKL1 and placebo groups, respectively, who had data for all visits (Table 2). Each of the three SGRQ domain scores showed similar patterns to the SGRQ total score, with mean decreases in the AKL1 group and mean increases in the placebo group but no significant differences between groups (Table 2). In the AKL1 treatment group, mean improvements in the LCQ and SGRQ scores, both absolute and relative to placebo, were greater than the MCID for those measures.

The LOCF analysis was consistent with the main intention-to-treat analysis; there were no significant differences between treatment groups (data not shown). 
Table 2 Mean change from baseline to outcome, and difference between treatment groups in mean change, in study endpoints after 8 weeks of treatment with AKLI or placebo

\begin{tabular}{|c|c|c|c|c|c|c|}
\hline & \multicolumn{2}{|c|}{ AKLI $(\mathrm{N}=20)$} & \multicolumn{2}{|c|}{ Placebo $(\mathrm{N}=13)$} & \multirow{2}{*}{$\begin{array}{l}\text { Difference in mean } \\
\text { change }(95 \% \mathrm{Cl})\end{array}$} & \multirow[t]{2}{*}{$P$-value ${ }^{a}$} \\
\hline & $\mathbf{n}$ & Mean (SD) & $\mathbf{n}$ & Mean (SD) & & \\
\hline \multicolumn{7}{|l|}{ Spirometry, postbronchodilator } \\
\hline $\mathrm{FEV}_{1}(\mathrm{~L})$ & 16 & $-0.1(0.2)$ & II & $-0.2(0.2)$ & $0.09(-0.07$ to 0.25$)$ & 0.27 \\
\hline FEV (\%predicted) & 17 & $-5.4(13.5)$ & 12 & $-5.0(7.1)$ & $-0.4(-9.2$ to 8.4$)$ & 0.92 \\
\hline 6-minute walk distance $(\mathrm{m})$ & 19 & $-5.5(6 \mid .4)$ & 13 & $-13(64.5)$ & $7(-39$ to 54$)$ & 0.74 \\
\hline LCQ score & 19 & $2.3(4.9)$ & 13 & $0.6(3.7)$ & $1.8(-1.5$ to 5.1$)$ & 0.28 \\
\hline SGRQ total score, units & 13 & $-7.7(11.7)$ & 9 & $1.5(9.3)$ & $-9.2(-19.0$ to 0.6$)$ & 0.064 \\
\hline SGRQ - symptoms domain & & $-6.2(14.6)$ & & $2.2(14.5)$ & $-8.5(-19.3$ to 2.4$)$ & \\
\hline SGRQ - activity domain & & $-10.0(17.0)$ & & $1.6(10.4)$ & $-11.6(-26.2$ to 3.0$)$ & \\
\hline SGRQ - impact domain & & $-4.9(11.7)$ & & $3.5(11.5)$ & $-8.4(-18.5$ to 1.8$)$ & \\
\hline CCQ score & 19 & $-0.01(0.6)$ & 13 & $0.1(0.7)$ & $-0.07(-0.5$ to 0.4$)$ & 0.76 \\
\hline Modified MRC dyspnea score & 17 & $-0.2(0.8)$ & 12 & $-0.2(0.6)$ & not applicable & 0.23 \\
\hline
\end{tabular}

Notes: The minimal clinically important differences are as follows: 1.3 for the LCQ (higher score is better); ${ }^{24} 4.0$ for the SGRQ (lower is better); ${ }^{26}$ and 0.4 for the CCQ (lower is better). ${ }^{27}$ aStudent's $t$-test for FEV, and FEV, \%predicted, 6-minute walk distance, CCQ, LCQ, and SGRQ, and $\chi^{2}$ test for the MRC comparing the two treatment groups for change from baseline to outcome. AKLI: AKL International, Ltd, Guernsey, UK.

Abbreviations: CCQ, Clinical COPD Questionnaire; Cl, confidence interval; FEV , forced expiratory volume in I sec; LCQ, Leicester Cough Questionnaire; MRC, Medical Research Council; SD, standard deviation; SGRQ, St George's Respiratory Questionnaire.

\section{Objective measures}

There were no significant differences between treatment groups in change from baseline to week 8 in lung function or the 6-minute walk distance (Table 2).

\section{Adverse events}

No COPD exacerbations were recorded during the study.

Five patients reported adverse events. Chest infections were diagnosed in one patient in each treatment allocation group: one in the placebo group at baseline (visit 2) and one in the AKL1 group at the final visit (visit 4). In the AKL1 group, one patient reported nightmares and one patient had right shoulder pain at the baseline visit, and one patient had influenza at the final visit.

\section{Discussion}

We found no significant improvement relative to placebo in the primary study endpoint of cough-related quality of life on the LCQ for patients with COPD who received add-on therapy with AKL1 twice daily for 8 weeks in this small, randomized, double-blind trial. Moreover, no significant differences between AKL1 and placebo groups were recorded for other study measures. Of note, however, AKL1 treatment resulted in mean improvements in LCQ and SGRQ, both absolute and relative to placebo, that were greater than the MCID for each of those measures. There were no exacerbations of COPD, and no AKL1-related safety concerns were raised during the study.
Complementary and alternative medicinal approaches have been used for centuries to treat a wide variety of ailments; however, there is a need for well-designed clinical trials to evaluate efficacy and safety of potential therapies. ${ }^{39,40}$ This is the first randomized controlled trial to investigate the efficacy of AKL1 as add-on therapy for patients with COPD and chronic cough. In a prior crossover study, in which AKL1 and placebo were each administered for 12 weeks as add-on therapy for 32 patients with asthma uncontrolled on standard treatment, no significant differences in lung function or secondary outcomes were recorded; however, trends in the patient-reported asthma control measures favored AKL1 therapy. ${ }^{20}$

We chose cough as the primary endpoint for this study, in part because the LCQ had shown trends to improvement in the previous asthma study; ${ }^{20}$ moreover, cough is a troublesome symptom for patients and responds poorly to existing therapies. However, our study, similar to the previous asthma study, ${ }^{20}$ was small and may have been insufficiently powered to detect a significant effect of AKL1 therapy. In addition, a longer course of treatment may have revealed a statistically significant divergence in outcomes for AKL1- and placebotreated patients.

A study limitation is that some outcome measures were not completed by all patients at all visits. To address this limitation, we conducted the LOCF analysis, whereby we were able to include data from almost all patients, thus increasing statistical power and reducing risk of bias from selective loss of patients. The results of the LOCF analysis, while not per 
protocol, and therefore exploratory, were consistent with those of the per-protocol analysis.

A strength of this study is that we enrolled patients from the community who were representative of the patient population with COPD seen in general practice, including male and female patients, the majority of them smokers or ex-smokers. Two patients were nonsmokers and had fixed airflow obstruction due to chronic asthma. Their disease is likely to be pathophysiologically different from that of the smokers, although a comparison was outside the scope of this study. We used multiple outcome measures, both objective and patient-reported, to assess the effects of therapy on the heterogeneous symptoms of COPD.

\section{Conclusion}

Results of this small study showed no significant improvement compared with placebo in the primary study endpoint of cough-related quality of life, as assessed using the LCQ, for patients with COPD receiving AKL1 as add-on therapy. However, we note that, in the AKL1 treatment group, the mean improvements in the LCQ and SGRQ scores, both absolute and relative to placebo, were greater than the MCID for those measures. Moreover, the substantial improvement in the SGRQ score among AKL1-treated patients suggests there may be a beneficial effect of treatment with AKL1. Further study is needed with a larger patient population and over a longer duration to better assess the effects of add-on therapy with AKL1 in COPD.

\section{Acknowledgments}

Assistance with the statistical analyses was provided by Stanley D Musgrave, MD. Editorial assistance was provided by Elizabeth V Hillyer, DVM, ELS. This research was funded by UK Respiratory Research Foundation (UKRRF) of the International Primary Care Respiratory Group (IPCRG).

\section{Disclosure}

Professor David Price has a stockholding with AKL who manufacture AKL1. The authors report no other conflicts of interest in this work.

\section{References}

1. Calverley PM. COPD: what is the unmet need? Br J Pharmacol. 2008; 155(4):487-493.

2. Yawn BP, Colice GL, Hodder R. Practical aspects of inhaler use in the management of chronic obstructive pulmonary disease in the primary care setting. Int J Chron Obstruct Pulmon Dis. 2012;7:495-502.

3. Restrepo RD, Alvarez MT, Wittnebel LD, et al. Medication adherence issues in patients treated for COPD. Int J Chron Obstruct Pulmon Dis. 2008;3(3):371-384.
4. George J, Kong DC, Thoman R, Stewart K. Factors associated with medication nonadherence in patients with COPD. Chest. 2005;128(5): 3198-3204.

5. Bourbeau J, Bartlett SJ. Patient adherence in COPD. Thorax. 2008;63(9): 831-838.

6. Decramer M, Janssens W, Miravitlles M. Chronic obstructive pulmonary disease. Lancet. 2012;379(9823):1341-1351.

7. Biswas S, Hwang JW, Kirkham PA, Rahman I. Pharmacological and dietary antioxidant therapies for chronic obstructive pulmonary disease. Curr Med Chem. 2013;20(12):1496-1530.

8. Barnes PJ. Corticosteroid resistance in patients with asthma and chronic obstructive pulmonary disease. J Allergy Clin Immunol. 2013; 131(3):636-645.

9. Marwick JA, Chung KF. Glucocorticoid insensitivity as a future target of therapy for chronic obstructive pulmonary disease. Int J Chron Obstruct Pulmon Dis. 2010;5:297-309.

10. George J, Ioannides-Demos LL, Santamaria NM, Kong DC, Stewart K. Use of complementary and alternative medicines by patients with chronic obstructive pulmonary disease. Med J Aust. 2004;181(5): 248-251.

11. Sharafkhaneh A, Velamuri S, Badmaev V, Lan C, Hanania N. The potential role of natural agents in treatment of airway inflammation. Ther Adv Respir Dis. 2007;1(2):105-120.

12. Guo R, Pittler MH, Ernst E. Herbal medicines for the treatment of COPD: a systematic review. Eur Respir J. 2006;28(2):330-338.

13. Anand P, Kunnumakkara AB, Harikumar KB, Ahn KS, Badmaev V, Aggarwal BB. Modification of cysteine residue in p65 subunit of nuclear factor-kappaB (NF-kappaB) by picroliv suppresses NF-kappaBregulated gene products and potentiates apoptosis. Cancer Res. 2008;68(21):8861-8870.

14. Dorsch W, Stuppner H, Wagner H, Gropp M, Demoulin S, Ring J. Antiasthmatic effects of Picrorhiza kurroa: androsin prevents allergenand PAF-induced bronchial obstruction in guinea pigs. Int Arch Allergy Appl Immunol. 1991;95(2-3):128-133.

15. Sutcliffe A, Hollins F, Gomez E, et al. Increased nicotinamide adenine dinucleotide phosphate oxidase 4 expression mediates intrinsic airway smooth muscle hypercontractility in asthma. Am J Respir Crit Care Med. 2012;185(3):267-274

16. Stefanska J, Sarniak A, Wlodarczyk A, et al. Apocynin reduces reactive oxygen species concentrations in exhaled breath condensate in asthmatics. Exp Lung Res. 2012;38(2):90-99.

17. Li GH, Lei XX, Yi YM, Xu BL, Wang HP, Du J. [Studies on the effect of Ginkgo biloba extracts on NF-kappaB pathway]. Zhong Yao Cai. 2008;31(9):1357-1360. Chinese.

18. Rogerio AP, Sá-Nunes A, Faccioli LH. The activity of medicinal plants and secondary metabolites on eosinophilic inflammation. Pharmacol Res. 2010;62(4):298-307.

19. Tang Y, Xu Y, Xiong S, et al. The effect of Ginkgo Biloba extract on the expression of PKCalpha in the inflammatory cells and the level of IL-5 in induced sputum of asthmatic patients. J Huazhong Univ Sci Technolog Med Sci. 2007;27(4):375-380.

20. Thomas M, Sheran J, Smith N, Fonseca S, Lee AJ. AKL1, a botanical mixture for the treatment of asthma: a randomised, double-blind, placebo-controlled, cross-over study. BMC Pulm Med. 2007;7:4.

21. Medicines and Healthcare Products Regulatory Agency, UK Department of Health. Good Manufacturing Practice. Available from: http:// www.mhra.gov.uk/Howweregulate/Medicines/Inspectionandstandards/ GoodManufacturingPractice/index.htm. Accessed April 1, 2014.

22. Global Strategy for the Diagnosis, Management, and Prevention of COPD. Global Initiative for Chronic Obstructive Pulmonary Disease (GOLD) [updated 2014]. Available from: http://www.goldcopd.org/. Accessed April 8, 2014

23. University of East Anglia. Treatment With AKL1 in Obstructive Airways Disease (The TAKL Study). Available from: http://clinicaltrials.gov/ ct2/show/NCT00920127. NLM identifier: NCT00920127. Accessed April 8, 2014 
24. Birring SS, Prudon B, Carr AJ, Singh SJ, Morgan MD, Pavord ID. Development of a symptom specific health status measure for patients with chronic cough: Leicester Cough Questionnaire (LCQ). Thorax. 2003;58(4):339-343.

25. Raj AA, Pavord DI, Birring SS. Clinical cough IV: what is the minimal important difference for the Leicester Cough Questionnaire? Handb Exp Pharmacol. 2009;(187):311-320.

26. Jones PW, Quirk FH, Baveystock CM, Littlejohns P. A selfcomplete measure of health status for chronic airflow limitation. The St George's Respiratory Questionnaire. Am Rev Respir Dis. 1992;145(6):1321-1327.

27. Jones PW. St George's Respiratory Questionnaire: MCID. COPD. 2005;2(1):75-79.

28. Kocks JW, Tuinenga MG, Uil SM, van den Berg JW, Stahl E, van der Molen T. Health status measurement in COPD: the minimal clinically important difference of the clinical COPD questionnaire. Respir Res. 2006;7:62.

29. van der Molen T, Willemse BW, Schokker S, ten Hacken NH, Postma DS, Juniper EF. Development, validity and responsiveness of the Clinical COPD Questionnaire. Health Qual Life Outcomes. 2003;1:13.

30. Clinical COPD Questionnaire. Available from: http://www.ccq.nl/. Accessed July 25, 2013.

31. Jones PW, Price D, van der Molen T. Role of clinical questionnaires in optimizing everyday care of chronic obstructive pulmonary disease. Int J Chron Obstruct Pulmon Dis. 2011;6:289-296.

32. Fletcher CM, Elmes PC, Fairbairn AS, Wood CH. The significance of respiratory symptoms and the diagnosis of chronic bronchitis in a working population. Br Med J. 1959;2(5147):257-266.
33. Stenton C. The MRC breathlessness scale. Occup Med (Lond). 2008;58(3):226-227.

34. Bestall JC, Paul EA, Garrod R, Garnham R, Jones PW, Wedzicha JA. Usefulness of the Medical Research Council (MRC) dyspnoea scale as a measure of disability in patients with chronic obstructive pulmonary disease. Thorax. 1999;54(7):581-586.

35. Cote CG, Casanova C, Marín JM, et al. Validation and comparison of reference equations for the 6-min walk distance test. Eur Respir J. 2008;31(3):571-578.

36. Cote CG, Pinto-Plata V, Kasprzyk K, Dordelly LJ, Celli BR. The 6-min walk distance, peak oxygen uptake, and mortality in COPD. Chest. 2007;132(6):1778-1785.

37. [No author listed]. Standardization of Spirometry, 1994 Update. American Thoracic Society. Am J Respir Crit Care Med. 1995;152(3): 1107-1136.

38. Miller MR, Hankinson J, Brusasco V, et al. Standardisation of spirometry. Eur Respir J. 2005;26(2):319-338.

39. An X, Zhang AL, May BH, Lin L, Xu Y, Xue CC. Oral Chinese herbal medicine for improvement of quality of life in patients with stable chronic obstructive pulmonary disease: a systematic review. J Altern Complement Med. 2012;18(8):731-743.

40. Sorkness RL. CAM and respiratory disease. Nutr Clin Pract. 2009;24(5): 609-615.
International Journal of COPD

\section{Publish your work in this journal}

The International Journal of COPD is an international, peer-reviewed journal of therapeutics and pharmacology focusing on concise rapid reporting of clinical studies and reviews in COPD. Special focus is given to the pathophysiological processes underlying the disease, intervention programs, patient focused education, and self management protocols.

\section{Dovepress}

This journal is indexed on PubMed Central, MedLine and CAS. The manuscript management system is completely online and includes a very quick and fair peer-review system, which is all easy to use. Visit http://www.dovepress.com/testimonials.php to read real quotes from published authors. 